\title{
Mãos de Vida na prática educativa: a Roda da Saúde no Circulo Transdisciplinar de Saúde Integral
}

\author{
Maria Glória Dittrich * \\ Vanderlea Meller ${ }^{* *}$ \\ Claiza Barretta ${ }^{* * *}$ \\ Maria Carolina Ulrich ****
}

\begin{abstract}
Resumo
O artigo apresenta práticas educativas efetivadas a partir da tecnologia social nomeada Círculo Transdisciplinar de Saúde Integral - CiTranSI - desenvolvida pelo projeto de extensão "Mãos de Vida", da UNIVALI, em Itajaí - SC. O projeto promove educação em saúde, estabelecendo ação transdisciplinar, em prol do fortalecimento da condição humana para a cidadania, com 20 jovens em vulnerabilidade social, que frequentam o espaço educativo Lar da Juventude de Assistência e Educação - Parque Dom Bosco, às sextas-feiras. São realizadas oficinas criativas dentro da transdisciplinaridade e ecoformação. A proposta educativa mobiliza um trabalho de fortalecimento e qualificação da atuação docente e discente universitário, para práticas que valorizam e efetivam ações educativas que consideram a complexidade do conhecimento, criativas e humanizadas, em diferentes especificidades nas áreas das ciências humanas e da saúde, permeadas pelas ciências da vida. Os resultados apresentam ampliação da interconexão de saberes, de diálogos, da ética nas aprendizagens de respeito no encontro com o outro, da reflexão e tomada de consciência sobre o cuidado de si e da natureza, com sentido para um viver saudável, bem como, o fortalecimento do foco de atenção na reflexão e reconhecimento da condição humana e de vínculos afetivos nas relações estabelecidas.
\end{abstract}

Palavras chave: CiTranSI, prática educativa, transdisciplinaridade.

Hands of Life in educational practice: the Wheel of Health on the Transdisciplinary Circle for Integral Health

Professora, Pesquisadora do Programa de Mestrado de Gestão de Políticas Públicas e do Curso de Enfermagem da Universidade do Vale do Itajaí - UNIVALI (SC/Brasil). Coordenadora do Projeto de Extensão “Mãos de Vida” da UNIVALI. E-mail: gloria.dittrich@unibali.br

** Professora do curso de Educação Física da Universidade do Vale do Itajaí - UNIVALI (SC/Brasil). Integrante do Projeto de Extensão "Mãos de Vida" da UNIVALI. E-mail: vanderlea@univali.br

*** Professora do curso de Nutrição da Universidade do Vale do Itajaí - UNIVALI (SC/Brasil). Integrante do Projeto de Extensão "Mãos de Vida” da UNIVALI. E-mail: claiza@univali.br

**** Acadêmica de Enfermagem da Universidade do Vale do Itajaí - UNIVALI (SC/Brasil). Integrante do Projeto de Extensão "Mãos de Vida” da UNIVALI. E-mail: mariaulrich@edu.univali.br 


\begin{abstract}
:
The article presentes the educational practices made from the social technology named Transdisciplinary Circle of Integral Health - CiTranSI - developed by the extension project "Mãos de Vida" in UNIVALI in Itajaí - SC. The project promotes health education, establishing disciplinary action in support of the strengthening of the human condition for citizenship, with 20 young people in social vulnerability, attending the educational space Home of Youth, Care and Education - Parque Dom Bosco, on Fridays. Creative workshops are held within the transdisciplinary and eco-formation practice. The educational proposal mobilizes a work of strengthening and qualification of teaching performance and university students to practices that value and actualize educational actions that consider the complexity of knowledge, creative and humanized, in different specific areas of the human sciences and health, permeated by life sciences. The results show expansion of the interconnection of knowledge, dialogue, ethics in learning to respect with others,

reflection and awareness of the care of oneself and nature, with regard to healthy living, as well as the strengthening the focus of attention in reflection and recognition of the human condition and affective bonds in established relationships.

Keywords: CiTranSI, educational pratice, transdisciplinary.
\end{abstract}

\title{
Introdução
}

O projeto de extensão da UNIVALI, "Mãos de Vida”, promove educação em saúde, estabelecendo ação transdisciplinar, em prol do fortalecimento da cidadania, com jovens em condição de vulnerabilidade social, oriundas dos bairros Nossa Senhora das Graças, Ressacada e Carvalho que frequentam o Instituto Lar da Juventude de Assistência e Educação - Parque Dom Bosco. A proposta educativa, criativa, mobiliza um trabalho de fortalecimento e qualificação da atuação docente para práticas que valorizam e efetivam ações educativas com profissionais em conexão, das diferentes especificidades da área da saúde e das humanas. O projeto está sendo efetivado há cinco anos, gerando impactos sociais, acadêmicos e profissionais, envolvendo produções tecnológicas na educação e no cuidado em saúde, as quais são realizadas por uma equipe de professores de oito cursos do Centro de Ciências da Saude da UNIVALI, envolvendo também conhecimentos da Filosofia e da Arteterapia. Participam da equipe de trabalho professores e alunos da Universidade. Na consolidação da proposta, os professores mobilizam, constantemente, estudos e reflexões sobre os espaços, metodologias e pessoas assistidas a fim de promover a educação em saúde e favorecer o ser cidadão na comunidade. As práticas dinamizam a criatividade nas aprendizagens ampliadas no cuidado à saúde e educação e no fortalecimento de vínculos sociais humanizados.

$\mathrm{Na}$ educação em saúde com os jovens em vulnerabilidade social são valorizadas 
ações criativas conjuntas entre os professores, alunos bolsistas e voluntários, garantindo princípios do pensamento complexo e da ecoformação, que são integradores e fundamentais para ações contextualizadas na educação em saúde, no cuidado à saúde e na qualidade de vida. Entende-se segundo Torre; Moraes et al. (2008), que a eco formação projeta um novo olhar sobre o conhecimento e a prática educativa. Ela é uma maneira sintética, integradora e sustentável de entender a ação formativa, sempre em relação ao sujeito, à sociedade e à natureza. Ela oportuniza a criação de vínculos interativos afetivos-cognitivos desde o natural, o pessoal, o social e a experiência de transcendência.

No projeto, os processos reflexivos das práticas e integralizadores dos saberes referentes à saúde são efetivados pela proximidade do compartilhamento de seres com seus saberes e ações criativas, com postura inter e transdisciplinar, nas áreas de: Educação Física, Filosofia, Arteterapia, Psicologia, Enfermagem, Medicina, Música, Nutrição, Farmácia e Fisioterapia. A interação entre professores e alunos, na intencionalidade da proposta, no planejamento e efetivação metodológica garante a dinâmica transdisciplinar e potencializa a complexidade do conhecimento. Para Morin (2006), a palavra complexidade só pode exprimir nosso incômodo, nossa confusão, nossa incapacidade para definir de modo simples, para nomear de modo claro, para ordenar nossas ideias. Portanto, ocorre um processo de abertura para o conhecimento, no qual o pensamento simplificador, reducionista e desarticulado é desconstruído, dando evidência para o pensamento integrador, provocando a dinâmica ordem-desordem.

Neste contexto a complexidade é uma palavra-problema e não uma palavrasolução. (MORIN, 2006). A prática educativa estruturada no pensamento complexo oportuniza a problematização, pois exige um olhar inclusivo, integrador, multidimensional, criativo, crítico sobre o ser humano, sobre a sociedade, sobre a natureza e sobre o conhecimento. O desafio é construir aprendizagens com sentido para o ser humano, buscando encontrar ligações e promover religações de saberes e fazeres. Pois, como diz Moraes (2014), nossa realidade é constituída de padrões de interconexões e de inter-relações multidiversas na ligação sujeito-objeto.

A postura transdisciplinar é essencial para colocar em evidência ações que interliguem o conhecimento e o sujeito da aprendizagem em vulnerabilidade social. Com efeito, é do diálogo articulador e problematizador de saberes que se constroem e se desconstroem relações e conhecimentos, os quais trazem uma dinâmica carregada de significados existenciais, dentro da cultura na sociedade e na natureza. Dentro das atividades do projeto de Extensão Mãos de Vida, a necessidade de conexão entre os saberes é indiscutível na busca por um saber com sentido para a vida. Como afirma Morin (1997), a partir do momento em que lançamos uma ação no mundo, essa vai deixar de obedecer 
às nossas intenções, vai entrar num jogo de ações e interações do meio social no qual acontece, e seguir direções muitas vezes contrárias daquela que era nossa intenção. A visão de Morin vem colaborar com as possibilidades de efetivação do processo educativo criativo desde a interconexão que surge entre os saberes e o mundo da vida, pois, é verdade, lá onde o pensamento simplificador falha, a visão da complexidade oportuniza a integração de saberes correspondentes às formas de ser, que põe ordem, clareza, distinção e precisão no conhecimento, que se explicita na realidade vivida.

Numa prática educativa, criativa, o pensar transdisciplinar ao tratar do conhecimento torna-se fundamental contemplar as conexões de ideias, pois elas mobilizam ação que integra da melhor forma possível os modos simplificadores de pensar, mas recusa as consequências mutiladoras, redutoras, unidimensionais e finalmente ofuscantes de uma simplificação que se considera reflexo do que há de real na realidade. (MORIN, 2006). Portanto, a constante tensão está no propósito de um trabalho que contempla o conhecimento, a construção de saberes, numa lógica não fragmentada e reducionista, levando em consideração que o conhecimento nunca é acabado, mas é processo de construção e desconstrução, para a descoberta de novos formas de explicar o real vivido. A partir de tais propósitos é preciso ter clareza sobre:

O que é a complexidade? A um primeiro olhar, a complexidade é um tecido (complexus: o que é tecido junto) de constituintes heterogêneas inseparavelmente associadas: ela coloca o paradoxo do uno e do múltiplo. Num segundo momento, a complexidade é efetivamente o tecido de acontecimentos, ações, interações, retroações, determinações, acasos, que constituem nosso mundo fenomênico. Mas então a complexidade se apresenta com os traços inquietantes do emaranhado, do inextricável, da desordem, da ambiguidade, da incerteza. (MORIN, 2006)

A complexidade está presente nos elementos diferentes que são inseparáveis, pois constituem um todo, portanto, na prática educativa o propósito é abordar e garantir a teia que se forma desde a conexão dos saberes, das relações, dos fenômenos que envolvem as pessoas. A complexidade da relação proposta por Morin (2006) ordem/desordem/organização, indica que os fenômenos desordenados são necessários em algumas condições e casos. Pois, na prática educativa, os momentos de inter-relações entre professor-aluno-conhecimento-sociedade-natureza ocorrem, na corporeidade do ser humano, numa recursividade, sinergética, de processos vitais-cognitivos que são, num primeiro momento, desordenados, mas que são promissores para que surjam fenômenos organizados de aprendizagens significativas para o aprendente. 
Na perspectiva dessa ideia, Moraes (2014) afirma que na educação a transdisciplinaridade pode ocorrer na vivência humana como o "surgimento da escala quântica, invisível aos nossos órgãos de sentido". Isso remete a experiência do fenômeno do "vazio" - o não-ser., que muitos gregos antigos falavam. Mas, reforça Moraes (2014) que o vazio quântico está cheio de energia, de potencialidades e possibilidades. É o mundo da criatividade, das Mãos de Vida (professores e alunos), que trazem a emergência da mudança, da auto-organização, da transcendência como processo criativo de interação constante para a transformação do ser-no-mundo, como dizia Heidegger. Com efeito, esse processo transdisciplinar vela e desvela, pouco a pouco, nas diferentes linguagens do ser humano, o impacto de uma prática que contribui para o fortalecimento da expansão da criatividade humana na dinâmica ordem-desordem/ junção/disjunção como pensou Morin (2006).

Dentro desta perspectiva de pensamento, este artigo apresenta uma prática educativa criativa desde a metodologia do Circulo Transdisciplinar da Saúde aplicada com jovens em vulnerabilidade social, realizada dentro do Projeto de Extensão "Mãos de Vida, da UNIVALI, no Parque Dom Bosco, em Itajaí - SC. Primeiramente mostrarse-á a metodologia nos seus três movimentos que oportuniza a organização da prática educativa, a qual foi desenvolvida tendo em vista o cuidado à saúde do ser humano na educação. Em seguida se apresenta a explicação descritiva sobre a prática criativa com base na arte musical dentro de uma das estratégias na referida metodologia supracitada - a "Roda da Saúde" e por último mostra-se o resultados alcançados.

\section{A metodologia do Circulo Transdisciplinar de Saúde Integral - CiTranSI}

Com um olhar sobre o ser humano como um ser multidimensional, complexo, de natureza criativa e saudável, utiliza-se para estruturar as ações educativas no cuidado aos jovens em situação de vulnerabilidade social, a - Tecnologia Social - CiTranSI, Essa metodologia possibilita a proximidade no acolhimento ao ser humano, visando uma maneira integradora, inclusiva de ser no diálogo reflexivo para articular o sentir, o pensar, o agir e o conviver nos processos de aprendizagens significativas.

O desenvolvimento do trabalho dá-se em três movimentos, que formam a "Roda da Saúde" estratégia metodológica que ocorre dentro do trabalho. Essa promove didaticamente uma prática criativa desde a imagem de uma roda de conversa e tem como fundamento os pressupostos epistemológicos da Teoria do Corpo-Criante de Dittrich (2010), bem como, o desenvolvimento da tecnologia mencionada na organização metodológica procedimental em Dittrich, Bernardo e Barreta (2012); Dittrich, Meller e Giorgi (2013) e que se apresenta a seguir: 
1) Preparo do ambiente: o ambiente é preparado energeticamente para receber os jovens, num propósito acolhedor de amorosidade à vida. As cadeiras da sala são dispostas em círculo, para a efetivação simbólica em diferentes linguagens e propósitos temáticos emergidos na Roda da Saúde. É escolhida uma música e uma mensagem visual em Arteterapia e Filosofia, além de dinâmicas no contexto da cultura dos sujeitos e manifestações da cultura de movimento;

2) Preparo da equipe transdisciplinar: realiza-se um movimento de concentração e energização dos processos vitais cognitivos da equipe transdisciplinar (professores e alunos bolsistas), que se dá por meio do diálogo para dinamizar a abertura de consciência no propósito do trabalho e movimentos corporais para o reforço da concentração, da consciência individual e interatividade de todos os envolvidos nas ações educativas, para a escuta acolhedora e as intervenções possíveis;

3) Movimento circular da saúde integral: momento no qual recebe-se os jovens com tudo o que a equipe preparou. Iinicia-se a ação educativa transdisciplinar para o cuidado à saúde. Ocorrem diversas práticas com foco no ser criativo e problematizador, envolvendo todos de maneira integrada:

- Recepção dos jovens: Fala inicial de acolhimento e boas vindas com música e mensagem. Apresenta-se com uma postura de acolhimento amoroso e todos ficam sentados em círculo formando um símbolo de unidade vital-cognitiva, integradora e complexa, criativa e inteligente, nos seus diferentes saberes e sentimentos pessoais. $\mathrm{O}$ grupo inicialmente participa ouvindo ou cantando uma música tocada por um aluno bolsista do curso de música, ou por meio de vídeo clip. Além disso, projetam-se imagens cromoterapêuticas e são realizadas dinâmicas que envolvem expressividade e diversas formas de linguagem corporal;

- Apresentação do tema específico: são realizadas atividades que mobilizam o acesso ao conhecimento, à reflexão interativa vibracional da música, das atividades específicas ao tema do dia e dos saberes envolvidos que cada um apresenta. Dinamiza-se temas ligados ao ser humano, à vida, à saúde, à ciência e à espiritualidade, visando à autorreflexão para a educação em saúde e elevação da autoestima e descoberta de sentido de vida. Estimula-se a percepção sobre o espaço de pertencimento na relação grupal, como prática educativa que oportuniza conhecimentos, posturas no pensar e conviver. Essas emergem desde diálogos educativos em diferentes linguagens de arte que se traduzem em vivênciais e experiências, que trazem algum sentido para a vida dos participantes. Ocorrem muitas ações pedagógicas envolvendo textos, registros ilustrativos por meio da arte, vídeos, imagens, músicas, exercícios corporais, construção e exploração de recursos didáticos, além do contato com a natureza como processo terapêutico. 
- Reencontro do ser integral na saúde: acontece na retomada e continuação da dinâmica da "Roda da Saúde" quando todos os jovens em círculo, desenvolvem ações com a arte, com a filosofia, com a psicologia, com a educação fisica e a nutrição as quais mobilizam a ressignificação dos conhecimentos temáticos envolvidos. Ao término das reflexões existe um momento para escutar e/ou cantar novamente uma música, a qual geralmente é elegida pelos jovens ou criada por eles. O intuito desta atividade final é a harmonização do fluxo energético das dimensões físicobiológica, psíquica, espiritual e social, tendo em vista a tomada de consciência sobre o ser e sua saúde, despertando para a criação e aprofundamento de laços sociais, afetivos e de conhecimento sobre a realidade, mas que possa trazer sentido a vida.

\section{Abrindo a explicação sobre prática educativa no CiTranSI}

As ações propostas pelo projeto "Mãos de vida" são articuladas transdisciplinarmente por meio dos saberes e atuação da equipe de trabalho multidisciplinar. Para Torre (2008) um olhar 'Trans' tem seus impactos e relevância que vão além do conhecimento porque é uma maneira de saber, de saber fazer, de saber ser e estar em qualquer atividade humana. A prática transdisciplinar oportuniza um constante aprender, dentro de uma abertura à descoberta de novos saberes e formas de viver a cidadania, que vai se construindo nas relações de conhecimento, de acolhimento, assessoramento e capacitação. Logo, entende-se que o pensar e o agir, na educação em saúde, compreende a complexidade das relações sociais e políticas das pessoas nas entidades assistidas e dos profissionais da instituição assistente - Univali, nas suas especificidades, funções e saberes, tendo em vista o fortalecimento da cidadania, na luta pela elevação da qualidade de vida.

A partir da visão de ser humano complexo nas suas dimensões biofísico-psíquico-espiritual-sócio-econômico e cultural (DITTRICH, 2010; 2013), as ações de educação em saúde emergem na ótica da ética e da moral, por princípios de respeito a si e ao outro, no enfrentamento das dificuldades e potencialidades. A educação no campo não formal tem um potencial de organização ampliado e flexível, portanto envolve diferentes áreas do saber para a educação dos jovens. Portanto a saúde é contemplada nos processos reflexivos em busca da valorização e do sentido da vida. Para Torre (2008) o campo da atitude transdisciplinar busca a compreensão e complementaridade do que ocorre na vida e no universo. Também no propósito da ecoformação,

como uma maneira de buscar o crescimento interior, a partir da interação na interação multissensorial com o meio humano e natural, de forma harmô- 
nica, integrada e axiológica. Tentando ir além do individualismo, do cognitivismo e do utilitarismo do conhecimento. Partindo do respeito à natureza (ecologia), levando em consideração os outros (alteridade) e transcendendo a realidade sensível (transpersonalidade). (TORRE; MORAES, 2008).

O desenvolvimento das práticas ocorre com abertura no diálogo interelacional, criativo e de aceitação para aprender e ensinar uns com outros. Visa a reflexão permanente sobre diferentes temas por meio de diferentes recursos didáticos como textos, filmes, imagens, histórias de vida, música...Por tratar-se de uma experiência inovadora as atividades articuladoras de abertura transdisciplinar, visam atingir o empoderamento da pessoa para a sua cidadania, dentro de uma visão de educação em saúde ampliada, as quais consideram o ser humano como um ser complexo constituido primariamente pelas dimensão biofísica, psíquica e espiritual, e secundariamernte pelas dimensãos social, cultural e ambiental. (DITTRICH, 2010; 2011, 2013). Para isto, a prática é constituida de vários professores que se conectam com seus alunos desde seus saberes e suas formas de ser e de agir nas vivências de aprendizagens para o ser saudável. Para entender a proposta ilustra-se abaixo a teia da complexidade, transdisciplinar dos professores e seus conhecimentos (Figura 1)

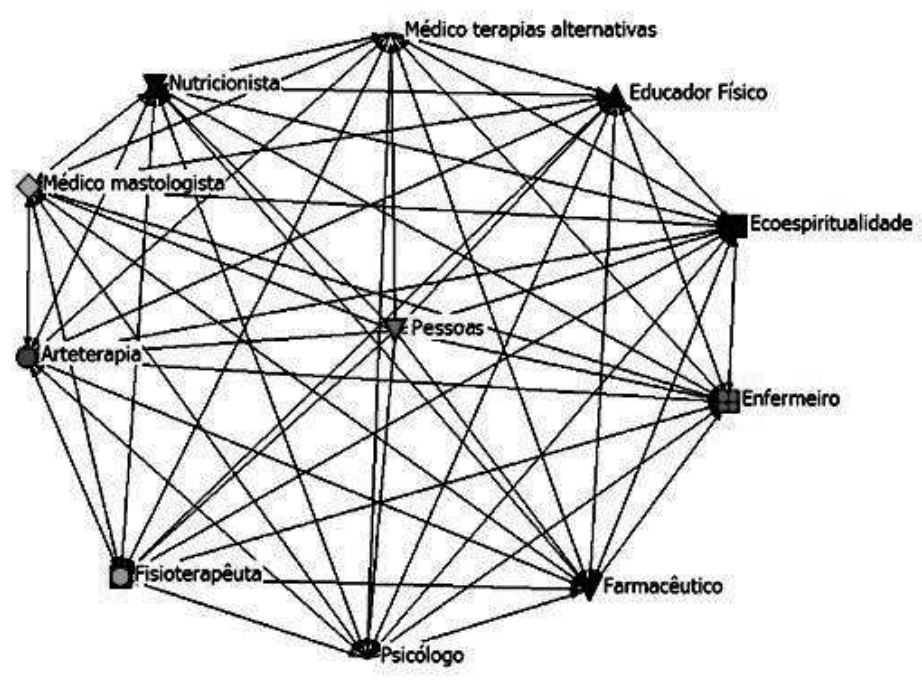

Figura 1 - Teia transdisciplinar de atuação profissional no CiTranSi 
Este suporte humano educativo bio-psíquico-espiritual, social, e científico é formado transdisciplinarmente por meio de laços sociais, afetivos e de interfaces de conhecimento e de tecnologias no cuidado educativo à saúde, os quais podem oportunizar práticas integradoras, norteadas pelo princípio ético do respeito à vida, que se manifesta em cada pessoa envolvida, seja o profissional, o acadêmico (estagiário, bolsista, voluntário, pesquisador) ou a pessoa que busca assistência - parceiros institucionais e outros. As pessoas ligadas ou unidas por laços de afeto, conhecimento, consideração, confiança, entre outros, podem influenciar mudanças no comportamento e na percepção das pessoas com relação a si mesmo, ao outro, à sociedade e a natureza.

As dinâmicas nos encontros com os jovens são organizadas de acordo com a proposta da metodologia CiTranSI, no propósito da "Roda da Saúde". No diálogo entre os participantes (alunos e professores) é promovido relações de compartilhamento e reflexões em torno do tema saúde e a relação com a vida.

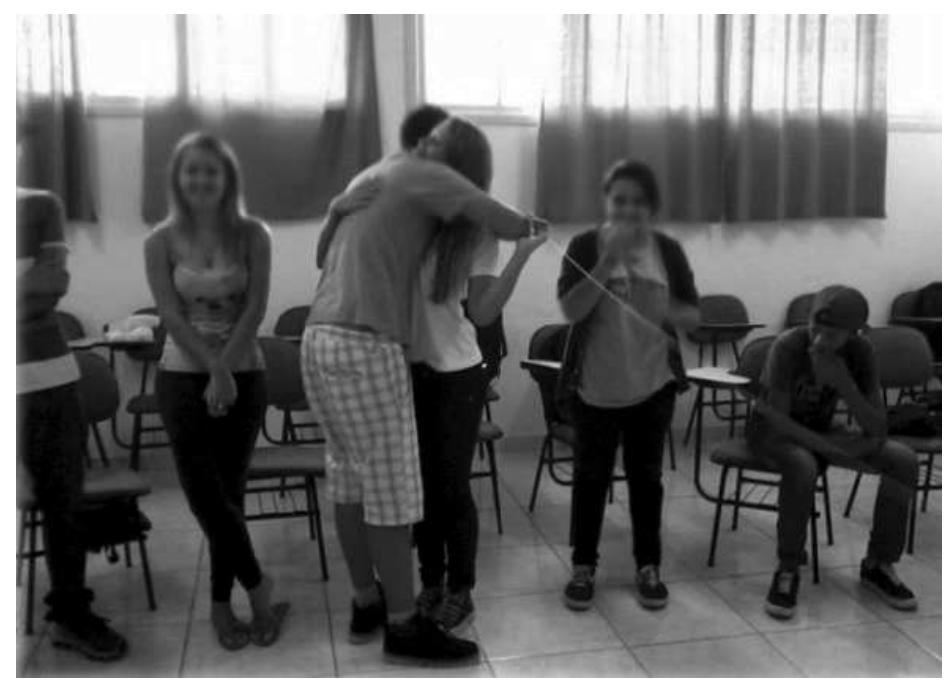

Figura 2 - Momento de acolhimento entre os alunos

A criatividade na musicalidade torna-se um meio didático e arteterapêutico de expressão e acolhimento do grupo, quando a harmonização inicial é promovida. Em cada oficina a música é, geralmente, escolhida pelos jovens e também representa a expressão e preferência musical do grupo, refletindo as preferências de cada um, a inserção cultural e situação social. A "Roda da Saúde" como dinâmica metodológica 
educativa busca pensar, expressar e refletir sobre o fortalecimento da vida no bem viver saudável, problematizando e identificando o que é qualidade de vida e o sentido de existir. Como dizia Frankl (2004, 2006): quem tem um porque viver encontra um o que fazer e um para que realizar seus atos existenciais.

No desenvolvimento do processo criativo do aluno, como vivência de ampliação do seu pensar e seu agir, ocorre também à expressão das percepções dele por meio de desenhos, registros escritos, expressão corporal, que estão mostrando formas de encontrar proximidade e autoafirmação nas inter-relações com o outro e com o conhecimento relacionado com algum sentido para o seu viver em sociedade. Dittrich (2011), afirma que na educação em saúde o ser humano vive o emocionar e o raciocinar como manifestações intrínsecas ao processo da auto-organização (criatividade) do seu corpo-criante nas relações micro e macrocósmicas e que atravessam as suas dimensões biopsico-espirituais, sociais e ambientais.

Nessa direção, Dittrich compartilha com Morin (2011), em torno da necessidade de se reconhecer o enraizamento da pessoa no cosmo físico e na esfera viva. É fundamental perceber para prática educativa a condição cósmica do ser humano - acolhendo uma interação do universo de pessoas numa dinâmica, auto-organizativa, viva, onde atua de modo complementar, concorrente e antagônico, a ordem, a desordem e a organização. Com efeito, numa prática estruturada na abordagem da complexidade da vida da vida na natureza, o ser humano como ser vivo precisa reconhecer que é também o resultado sagrado da gênese da vida de uma diáspora cósmica, que forjou a existência solar e logo, a sua condição de terrestre, mas também de pertencimento cósmico. É fundamental para processos educativos, focados na condição humana e que alcança várias dimensões já supracitadas, realizar metodologias que alcancem uma visão integral sobre o ser humano, o conhecimento e o seu lócus de vida.

Na proposta de atuação e construção do conhecimento contempla-se o constante reconhecimento e envolvimento do ser humano e seus enraizamentos familiares, sociais e ambientais. Considera-se a inteireza do ser, os processos de ordem e desordem, permitindo e mobilizando o fluxo dinâmico dos saberes envolvidos. Destaca-se o quanto os saberes estão conectados e a necessidade de mobilizar a criatividade à abertura para dinâmica de cuidado educativo estabelecendo uma teia de diálogos entre os conhecimentos e os multidiversos professores e alunos. 


\section{Mãos de Vida: os resultados educativos alcançados}

A postura transdisciplinar tornou-se fundamental na proposta no projeto de extensão "Mãos de vida". Os impactos indicaram a validade das ações educativas na perspectiva ecoformativa e transdisciplinar para o reconhecimento da saúde integral por parte dos jovens. As questões culturais presentes nos saberes e nos sujeitos foram contextualizadas e possibilitaram reflexões de conhecimentos e valores para a vida, como também colaboraram com a identificação do pertencimento social. Na prática, tornou-se fundamental a contemplação de ações e saberes, que valorizassem o ser humano na sua integralidade, desarticulando do predomínio do olhar biologicista. Como diz Suanno (2012), a concepção de ser humano determina o olhar do professor sobre a sua prática.

A cada oficina o diálogo criativo e reflexivo efetivou ações educativas que valorizaram a integralidade do ser humano na sua condição vital. A visão ecoformativa promoveu a valorização da preservação e manutenção da vida. Os jovens vinculados à percepção de integralidade humana e consciência ecológica, para interação no meio onde vivem, sentiram-se corresponsáveis pelas suas vidas. Com efeito, a metodologia aplicada criou consciência de grupo numa prática educativa emancipadora, pois, tornou-se evidente as aprendizagens dos alunos para cuidado humanizado e a compreensão de temas envolvendo saúde integral e relações estabelecidas para paz, alimentação e exercícios que mobilizam o movimento saudável.

Os estilos de vida positivos para a saúde e qualidade de vida foram potenciais para o fortalecimento corporal e ampliação das interações e autoestima. A atenção promovida sobre a relação corpo-sociedade-natureza e saúde integral favoreceram uma nova compreensão sobre as condições de saúde dos jovens. Vários fatores expressos pelos jovens por meio do diálogo reflexivo e mobilizados pelas diversas áreas e saberes, ampliou um olhar inclusivo sobre as dimensões do humano e relações potencializadas.

Destacam-se as ações transdisciplinares realizadas, nas quais foram estabelecidas aproximações de saberes específicos com a área da música, promovendo o compartilhamento e a solidariedade na descoberta de novos saberes e práticas com foco na compreensão da condição humana em sociedade. A música, como manifestação expressiva do ser, é uma linguagem que mobiliza a cultura e ações comunicativas carregadas de representações e valores culturais. Neste contexto, os jovens foram inicialmente incentivados a escolher uma música, a qual seria o hino do grupo, muitas opções surgiram onde foi possível identificar os desejos e valores presentes nos jovens. A princípio, muitas atitudes e expressões não colaboraram positivamente com a con- 
vivência e respeito ao grupo, como a agressividade, o bullying muito evidente, prejudicando a convivência. A proposta envolvendo a musicalidade mobilizou atitudes positivas e a convivência harmônica do grupo, dinamizando a interação e tomada de consciência para a convivência.

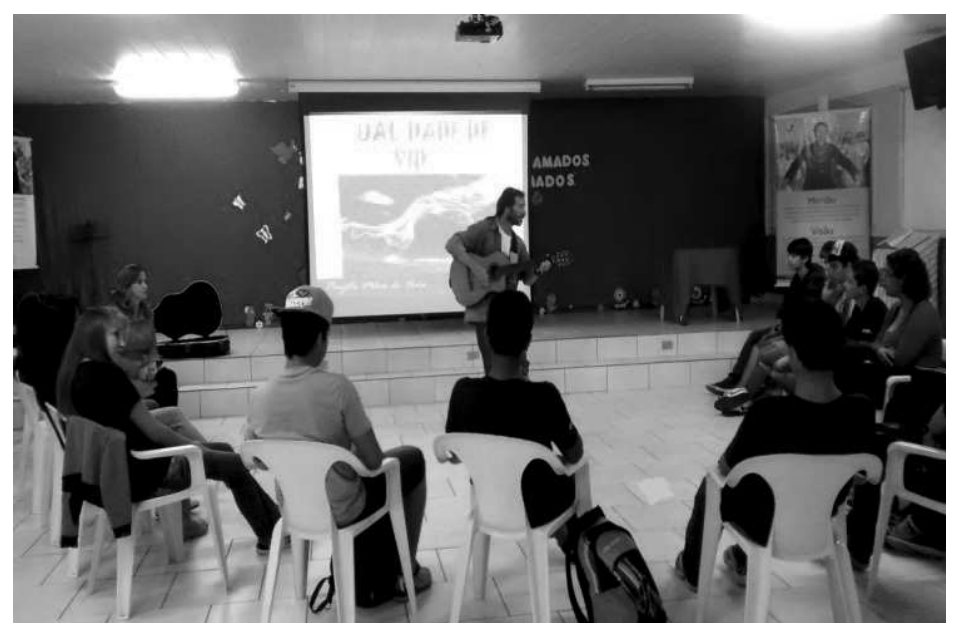

Figura 3 - Roda da Saúde - Dinâmica criativa com música, canto e filosofia.

A partir da leitura das músicas ocorreu o diálogo sobre as expressões que mobilizam as sensações mais intensas na música, a nível sensorial, foi possível identificar que ao cantar, os jovens ativaram mais potencial sensível, pois ao ler a letra o foco na racionalidade ficou mais evidente. O grupo aprendeu a problematizar sobre o significado das expressões presentes nas músicas e identificaram que muitos valores morais são expressos, atitudes sociais, desejos de sentimentos que envolvem amor, felicidade, paz, alegria de viver, entre outros. As músicas escolhidas pelos alunos revelaram a sensibilidade musical e criticidade do grupo. Exemplo: Celebrar - Jammil; Uma Noite e Tempos Modernos - Lulu Santos; Reggae das Tramanda - Armandinho; Lado Escuro da Lua - Capital Inicial; Colorir Papel - Jammil e Uma Noites; Desenho de Deus Armandinho.

Os jovens tiveram a tarefa de defender o porquê entendiam que música escolhida revelava algo para o sentido de suas existências para um viver saudável. Afirmam eles: A música Celebrar: "Faz se sentir melhor, fala de celebrar a vida e o que devemos fazer para nos sentirmos melhor." (jovem 1). A música Tempos Modernos: "Mostra o encorajar, buscar uma vida melhor e seguir em frente." (jovem 2). A música Reggae das 
Tramanda: "Faz pensar em ter contato com o mundo." (jovem 3). A música Colorir Papel: "Fala de aprender mais e do sentimento de que as coisas possam acontecer." (jovem 4). A música Lado Escuro da Lua: "Fala de querer o errado, do lado escuro da lua que pode ser sem sol, escuro da vida, as experiências da vida que devem ser de amor e de sentimentos bons." (jovem 5).

Foi muito interessante identificar o quanto a música mobilizou sentimentos bons e positivos nos alunos. Por meio da sensibilidade e da racionalidade prática inicial para prover a expressividade conseguimos identificar com muita contundência expressões que envolviam a desmotivação para a vida, a incompreensão sobre o outro e a falta de um sentido para a existência.

A educação deve conduzir à 'antropoética', levando em conta o caráter ternário da condição humana, que é ser, ao mesmo tempo, indivíduo- sociedade-espécie. Nesse sentido, a ética indivíduo-espécie necessita do controle mútuo da sociedade pelo indivíduo e do indivíduo pela sociedade, ou seja, pela democracia, a ética indivíduo-espécie convoca para o século XXI, a cidadania terrestre. (MORIN, 2011)

Após o envolvimento com escolhas musicais que realmente representassem a intencionalidade das práticas educativas como processo ecoformativo que considera a relação ser humano-sociedade-natureza e transcendência na sua condição humana, percebeu-se o despertar do ser sensível, dos sentimentos afetivos que foram potencializados positivamente, repercutindo na valorização de atitudes coerentes, com relações mais afetivas, com vontade de viver e compartilhar o amor, como alegria de viver simplesmente. Registra-se que para Morin (2011), o desenvolvimento da inteligência é inseparável do mundo da afetividade, isto é, da curiosidade, da paixão, que por sua vez são a mola da pesquisa filosófica ou científica.

A música "Tempos modernos" de Lulu Santos foi escolhida pela maioria dos jovens, para tornar-se o hino do grupo. Os principais argumentos que interferiram na escolha foram que a letra expressava sobre uma vida melhor no futuro e era o que todos desejavam perante as situações do presente, com pessoas mais sinceras e educadas. "Nos permitir" foi à frase mais evidenciada, no sentido de ações do bem, desejos positivos e conquistas, de sucesso nas relações, para um mundo melhor. A música acabou sendo o instrumento didático pedagógico de identificação pessoal-grupal e de articulação dos saberes e de atividades que se tornaram mais atrativos e prazerosos.

Foram realizadas atividades vinculadas ao meio ambiente onde os jovens interagiram na natureza. Uma atividade com resultados positivos foi realizada com olhos 
vendados e os jovens buscaram o ritmo interno dos batimentos do coração e mobilizados por este ritmo passaram a perceber também os ritmos da natureza, como o som das folhas, o canto dos pássaros, do vento... Impulsionaram-se a mover-se no espaço, nos diferentes ritmos, sentindo o som das folhas no chão... Cada um interagiu por meio da sensibilidade pessoal e estabeleceu conexão com o meio ambiente e com a natureza física e sensível do ser. Foi possível sentir o ambiente, as árvores, o solo, o ritmo da natureza e a ligação com o ritmo do próprio corpo. As experiências em contato com a natureza foram essenciais para os jovens estabelecerem conexão vital com as energias do eu e com as energias da natureza. Se muito bem o que há de comum ao gesto e ao seu sentido, por exemplo, à expressão das emoções e às próprias emoções: o sorriso, o rosto distendido, a alegria dos gestos contêm realmente o ritmo de ação, o modo de ser no mundo que são o próprio júbilo. (MERLEAU- PONTY, 1999). A criatividade envolvida na expressividade artística, como também da linguagem sistematizada nas reflexões temáticas filosóficas, foi dinamizada possibilitando aos jovens,

O seu fazer subjetivo, que auto-referente para a criação da sua obra e consequentemente, para o seu aprender, encontra uma maneira de expressar concretamente o que está se passando naquele momento na sua interioridade, a linguagem das imagens. Com efeito, a linguagem é constitutiva do ser homem. (DITTRICH, 2001)

Para ampliar a compreensão sobre o cuidado de si, consciência corporal e também favorecer a musicalidade, promoveu-se exercícios de respiração, no qual problematizamos e reaprendemos a respiração diafragmática, além da sua importância para o corpo, concentração e exercícios. Muitas músicas foram escolhidas para serem tocadas durante os encontros e muitas atividades foram mobilizadas com os jovens acompanhando os ritmos por meio do movimento corporal, de forma expressiva e sensível.

A partir do momento que a música passou a fazer parte do cotidiano, as relações e posturas individuais passaram a ter transformações importantes, pois todos passaram a ser mais afetivos, solidários e participativos nas conversas que evidenciaram reflexões e expressões sobre o que valorizam nas relações humanas e o envolvimento do corpo como presença e relação no mundo. As reflexões foram importantes para fortalecimento ético e moral, pois demonstraram valores e responsabilidade com a vida, pessoal e do outro. Além do hino do grupo, os jovens também escolheram dois videoclipes da canção "Tempos Modernos", os quais apresentavam imagens expressivas e foram muito significativos para sensibilização perante a letra da música. Um dos jovens falou que o primeiro vídeo era mais interessante, pois apresentava imagens 
positivas, com mensagens nas imagens que mostravam que é para viver e ser feliz, enquanto no segundo vídeo a mensagem que ficou mais evidente foi de que curtir a vida, ir para "baladas" e bebidas alcoólicas. Estas colocações provocaram questionamentos sobre as festas e atividade de vida saudável. Os jovens expressaram como a música mexe com os sentimentos e vontades das pessoas, como também desperta para outros pensamentos sobre a vida.

A filosofia fomentou os debates sobre o processo existencial do ser humano, na necessidade de ser coerentes com o que se pensa que é, e o que se é realmente. Os debates realizados no encontro foram de notável relevância para o aprofundamento do tema qualidade de vida, principalmente quando se trata da questão de "aproveitar a vida". Ficou evidente que os jovens conseguiram dialogar mais e tiveram envolvimento crescente nos encontros.

As formas expressivas evidenciadas pelos jovens foram diversas nas criações coreográficas, mobilizadas principalmente pela Educação Física. Por exemplo, a coreografia produzida por meio da língua de sinais (libras) que foi muito especial para sensibilização e respeito à linguagem apresentada, o grupo todo compartilhou da expressão. Caos e ordem se misturam na dança da partícula e da onda que subjaz toda a organização vital-cognitiva do corpo-criante e a criatividade emerge por um fazer subjetivo pictórico, que se traduz numa maneira de ser: a obra (DITTRICH, 2001).

Foi na dinâmica conectiva e integradora entre os saberes envolvidos, que a professora de filosofia e arteterapia evidenciaram o propósito de sentir e de ouvir o próprio corpo, pois nele e por ele surge o propósito da expressão criativa nos processos de criatividade, no aprender a aprender no mundo da vida, de um jovem em vulnerabilidade social. Nessa prática, a professora também dialogou com o grupo sobre as relações psicológicas envolvidas na formação humana e nas relações estabelecidas. Refletiu sobre como o inconsciente/consciente das pessoas registram as memórias que interferem na forma como elas se entendem e entendem o mundo e que se deve ser coerente com o que se pensa e age-se.

Nessa prática, a transdisciplinaridade toma um modo de viver a educação e a existência, logo, a educação em saúde passa a ser identificada na relação do ser humano em contato com o outro, no seu meio sociocultural e ambiental. Saúde é bem estar do ser humano, o equilíbrio entre as suas diversas dimensões que o constituem e que interferem na sua forma de ser de pensar, de fazer e de conviver no mundo da vida (ESPÍNDOLA; DITTRICH, 2015).

Muitas atividades foram desenvolvidas a fim de promover o reconhecimento e compreensão da criatividade emergente do corpo, amplamente, também para favore- 
cer a saúde e o viver saudável em sociedade. As questões emocionais que envolvem a relação do ser humano com seu próprio corpo, os desejos e o respeito também foram problematizados, pois muitas exigências são culturais e resultado de herança histórica. Para Merleau-Ponty (1999), a reflexão está implícita na dimensão de "Ser corpo e não ter corpo", pois o corpo é um nó de significações vivas que se expressa na dinâmica da percepção humana.

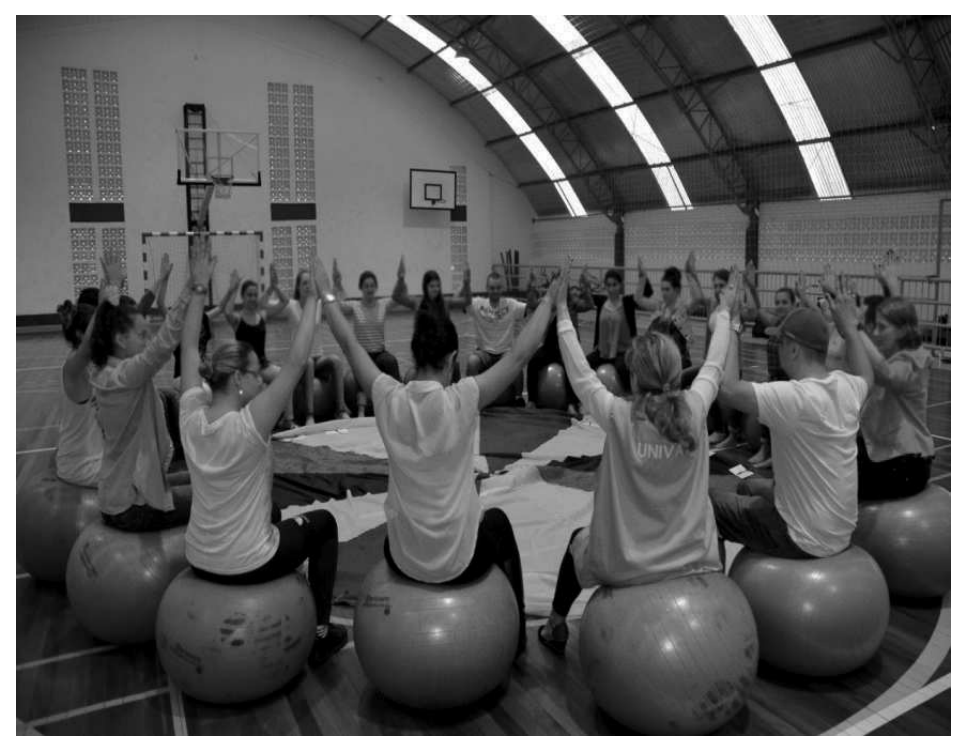

Figura 4 - Atividade criativa de dinâmicas corporais com bolas e mandala

Em virtude da agressividade interna e punitiva presente nos jovens as atividades que promoveram a expressão da agressividade, a catarse, foram fundamentais. Por meio de atividades com bola foi possível mobilizar movimento corporal, intencionalidade e expressão. As forças agressivas foram canalizadas do sujeito para o exterior. Houve a descoberta de algo como uma maneira de ser e sentir a vida pulsando como algo sagrado e que precisa ser respeitado e significado. Com efeito, no processo educativo e na emergência da criatividade desperta uma espiritualidade, como energia da vida sentida e percebida na relação com o fazer humano e que traz sentido para o viver. Como diz Frankl (2006), o sentido do viver está diretamente ligado à dimensão espiritual, que dinamiza a razão de viver do humano frente as adversidades existências. 
Os jovens identificaram uma energia forte que transcendia os seus corpos, uma energia que ajuda a ser forte, que é positiva, uma energia de vida, também reconheceram que é fundamental estar "de corpo inteiro" em todas as situações da vida. Com efeito, a partir das atividades que mobilizam o corpo surge a possibilidade mais ampla de movimento corporal e expressão com várias linguagens. Nas práticas criativas identificou-se o quanto as emoções foram equilibradas e os níveis de agressividade negativos para o ser na convivência na "Roda da Saúde" foram amenizados. São atitudes que garantem a vivências dos princípios éticos, pois devemos relacionar a ética da compreensão entre as pessoas com a ética da era planetária, que pede a mundialização da compreensão (MORIN, 2011).

\section{Considerações Finais}

A partir da perspectiva metodológica do CiTranSi foi possível promover a efetivação de uma prática pedagógica, criativa, transdisciplinar, de diálogo e contextualização de conceitos, com olhar para apreensão da complexidade fenomênica dos sujeitos envolvidos. Neste sentido, o ser humano e a natureza foram vividos na estrutura de suas complexidades, em busca da construção do conhecimento com sentido para a vida.

A perspectiva do projeto e da atuação dos professores foi dinamizada para a sensibilização da afetividade e da expressão da racionalidade criativa fruto do pensar, sentir e agir educativo e social, em cujo processo o objeto do conhecimento não é dominado apenas por uma área, mas na intercomplementaridade do ser e do saber para um viver saudável. Os impactos indicam a validade das ações educativas que estão sendo propostas pelo projeto, na Instituição Parque Dom Bosco, numa visão ecoformativa e transdisciplinar, para reconhecimento da saúde integral por parte dos jovens. Na proposta, de ação transdisciplinar, tornou-se fundamental a contemplação de ações e saberes que valorizam o ser humano na sua integralidade e criatividade , desarticulando do predomínio biologicista em educação e saúde. Ou seja, aquele que defender que a saúde é ausência de doença.

A visão ecoformativa promoveu a valorização da preservação e manutenção da vida pelos jovens, vinculados à percepção de integralidade humana, consciência ecológica para interação no meio onde vivem; empoderamento para cuidado humanizado; compreensão de temas envolvendo saúde integral e relações estabelecidas para paz, alimentação e exercícios; estilo e qualidade de vida positiva; ampliação das interações e autoestima. Corpo e saúde contemplados na visão ecoformativa favoreceram as 
condições de saúde dos jovens, reconhecidas por meio do diálogo reflexivo de relação sociocultural e ambiental.

Os jovens passaram a evidenciar seus sonhos, seus desejos e possíveis conquistas, portanto, assumiram responsabilidades próprias para melhorar, colaborar com a convivência no grupo e para uma sociedade melhor. Perante as aprendizagens desejadas os jovens foram mobilizados na "Roda da Saúde" para reflexão e expressividade artística, por meio de diferentes linguagens, do canto, da criação coreográfica da música, da dança, da arte onde tiveram a possibilidade de expressar os sentimentos envolvidos, como também a ressignificação de aspectos de suas vidas. Percebeu-se aprendizagens com sentido para a vida, sensíveis para ações e sentimentos positivos nos e para os jovens.

\section{Referências}

DITTRICH, M. G. Natureza e criatividade: o ensino da arte pictória. Itajaí: UNIVALI, 2001.

DITTRICH, M. G. Arte e criatividade. Espiritualidade e cura. Blumenau: Nova letra, 2010.

DITTRICH, M. G. A criatividade na teoria do corpo-criante: um ponto de partida á transdisciplinaridade e á inovação no ensinar. In TORRE, Saturnino de la; ZWIERWWICZ, Marlene; FURLANETTO, Ecleide Cunico. Formação docente e pesquisa transdisciplinar. Criar e inovar com outra consciência. Blumenau: Nova Letra, 2011.

DITTRICH, M. G.; BERNARDO, L.; BARRETA, C. Tecnologia de abordagem transdisciplinar para o cuidado às pessoas com câncer de mama. Saude \& Transformação Social. Florianópolis, v.3, n.3, p.44-51, 2012.

DITTRICH, M. G.; MELLER, V. A.; GIORGI, M. D. M. A roda da saúde: a sala de espera numa visão transdisciplinar do cuidado. In Saúde a contribuição universitária. Organizadoras Berenice Rocha Zabbot Garcia, Gladis Luisa Baptista. Joinville, SC: Editora da UNIVILLE, 2013.

ESPINDOLA, K. S.; DITTRICH, M.G. Arteterapia no cuidado integral à saúde. Itajaí: Editora da UNIVALI, 2015 
FRANKL, V. E. A presença ignorada de Deus. 8. ed. Petrópolis: Vozes, 2004.

FRANKL, V. E. Em busca de sentido: um psicólogo no campo de concentração. 22. ed. São Leopoldo: Sinodal; Petrópolis: Vozes, 2006.

FRANKL, V. E. Logoterapia e análise existencial. São Paulo: Editorial Psy II, 1995.

MERLEAU-PONTY, M. Fenomenologia da percepção. São Paulo: Martins Fontes, 1999.

MORAES, M. C. Educação e sustentabilidade: um olhar complexo e transdisciplinar. In: (Org.). MORAES, M. C.; SUANNO, J. H. O pensar complexo na educação. Sustentabilidade, transdisciplinaridade e criatividade. Rio e Janeiro: WAK, 2014.

MORIN, E. Os sete saberes necessários à educação do futuro. 8 ed. São Paulo: Cortez; Brasília, DF: UNESCO, 2011.

MORIN, E. Introdução ao pensamento complexo / Edgar Morin; tradução Eliane Lisboa. $5^{\mathrm{a} e d .}$ - Porto Alegre : Sulina, 2006.

MORIN, E. Complexidade e ética da solidariedade. In: (Org.) CASTRO, G. et al. Ensaios de complexidade. Porto Alegre: Sulina, 1997.

SUANNO, M. Reorganização do trabalho docente na educação superior. In: (Org.). SUANNO, M.; RAJADELL, N. Didática e formação de professores: perspectivas e inovações. Goiânia: CEPED, 2012.

TORRE, S. PUJOL, M. A.; MORAES, M.C. Trandisciplinaridade e ecoformação: um novo olhar sobre a educação. São Paulo: Triom, 2008.

Recebido em: 08 abril 2016.

Aceito em: 18 abril 2016. 